\title{
Lux Boreal: Fit/Misfit bajo la lupa del arte contemporáneo y sus nuevos modelos de producción
}

Lux Boreal: Fit/Misfit Under the Zoom of Contemporary Art and its New Production Patterns

\author{
Ana Lucía Piñán Elizondo
}

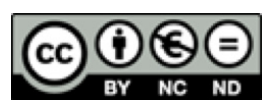

Esta obra está bajo una licencia Creative Commons

Reconocimiento-No comercial-Sin Obra Derivada 


\title{
Lux Boreal: Fit/Misfit bajo la lupa del arte contemporáneo y sus nuevos modelos de producción
}

\author{
Lux Boreal: Fit/Misfit Under the Zoom of Contemporary Art \\ and its New Production Patterns
}

\author{
Ana Lucía Piñán Elizondo ${ }^{1}$ \\ Benemérita Universidad Autónoma de Puebla \\ México
}

\begin{abstract}
Recibido: 2 de febrero del 2017 Aprobado: 30 de enero del 2018
\end{abstract}

\begin{abstract}
Resumen
Fit/MisFit, obra de la compañía de danza contemporánea Lux Boreal (en colaboración con Iseli-Chiodi Dance Company, agrupación procedente de Tijuana, Baja California, México) es analizada bajo lineamientos que emergen de un profundo acercamiento al texto La danza en el marco del arte moderno contemporáneo: los nuevos modelos de producción, de Marcelo Isse Moyano y a la discursividad dialógica que en él encuentran autores como Danto, Dickie, entre otros. Estos, vinculados con Lachino y el retrato escrito que hace de la escena mexicana actual, permiten postular a Fit/MisFit como una pieza auténticamente contemporánea por su correspondencia con las características del arte actual, su contexto y el abordaje de modelo de producción que planteó su construcción y su puesta en escena.
\end{abstract}

Palabras clave: posthistórico; transfiguración; juego; banalización; mundo del arte

1 Profesora e investigadora en la Benemérita Universidad Autónoma de Puebla, México. Doctoranda en Arte, Producción e Investigación en la Universidad Politécnica de Valencia, España. Correo electrónico: luannita@hotmail.com 
Lux Boreal: Fit/Misfit bajo la lupa del arte contemporáneo y sus nuevos modelos de producción Artículos

\begin{abstract}
Fit / MisFit, a work by Lux Boreal contemporary dance company (in collaboration with Iseli-Chiodi Dance Company, a group from Tijuana, Baja California, Mexico) is analyzed under guidelines that emerge from a deep approach to the text La danza en el marco del arte moderno contemporáneo: los nuevos modelos de producción, by Marcelo Isse Moyano and the dialogical discursiveness that writers such as Danto, Dickie, etc., found in it and who, linked with Lachino and her written portrait of the the current Mexican scene, allow Fit/MisFit to be nominated as a truly contemporary piece for its correspondence with the characteristics of current art, its context and the approach to production patterns that raised its construction and its staging.
\end{abstract}

Keywords: posthistorical; transfiguration; game; trivialization; art's world

ESCENA. Revista de las artes, 2018, Vol. 78, Núm. 1 (julio-diciembre), pp. 10-26. ISSN 2215-4906 
El presente análisis pretende ser un testigo crítico de las producciones contemporáneas de la danza mexicana, en general, y de la producción Fit/MisFit ${ }^{2}$ de la compañía $L u x$ Boreal de Tijuana, Baja California, en particular. Lo que procura articular la evidencia de su contemporaneidad desde un análisis teórico desprendido, principalmente, de textos del investigador Marcelo Isse Moyano, atravesados, a su vez, por el discurso de autores como Danto, Dickie, entre otros, quienes sirven como marco, en tanto justificación de la apuesta hecha por dicho evento como miembro legítimo, y no superficial, del universo llamado danza contemporánea. Los por qué esta obra y no otra tienen que ver, en primera instancia, con la oportunidad de explorar, analizar y, sobre todo, visibilizar la danza de calidad de México. En segunda instancia, se relaciona con la gran cantidad de características que, contenidas en la obra, y sin traicionar la estética de una compañía con más de 15 años de trayectoria, resultan evidencias de la contemporaneidad de la danza (y la cultura) mexicana.

Antes de entrar de lleno a las características de Fit/MisFit, se vuelve necesario el marco que permita leer y comprender, desde el mismo sitio, el punto de anclaje del trabajo. De la mano de Hayde Lachino ${ }^{3}$ se dibuja el panorama de la danza contemporánea en México. Principalmente, respecto a su producción y su consumo, lo que brinda cierta certeza respecto al terreno real en el que se aplicarán los conceptos y teorías abordadas más tarde. De Arthur Danto se toma la idea de la muerte del arte y de la transfiguración del lugar común, lo que permite situar, temporalmente, desde la posthistoria, la propuesta en términos de la definición del arte. Esto brinda una de las principales características que permiten que una propuesta aspire a pertenecer al universo de la danza (arte) contemporánea, mientras que Dickie aportará su Teoría institucional del arte. A partir de las teorías de los autores citados hasta aquí, a excepción de Lachino, se logra un diálogo en La danza en el marco del arte moderno contemporáneo: los nuevos modelos de producción, texto de Marcelo Isse Moyano (2013), que permite apuntar las pautas de lo que puede, o no, ser llamado danza contemporánea hoy. Justamente, de este autor es de quien se tomarán las características concretas a analizar a lo largo de la obra propuesta.

Con ayuda del marco anterior se podrá dibujar el tránsito de Fit/MisFit entre la idea de agotamiento de la danza o, en su caso, de la tendencia a lo puro y disciplinar como garantía de calidad y la sorpresa, el juego, lo autobiográfico, el pluralismo estético, entre otras, como

${ }^{2}$ La versión completa de la obra fue recuperada de https://vimeo.com/225706489

${ }^{3}$ Crítica de danza, productora, coreógrafa y videoartista. Realizadora de diversos documentales, cortometrajes y piezas de videoarte. Productora ejecutiva de espectáculos multimedia de danza y teatro. Ha trabajado como columnista y crítica en prestigiados periódicos de México, así como en revistas y publicaciones de arte.

ESCENA. Revista de las artes, 2018, Vol. 78, Núm. 1 (julio-diciembre), pp. 10-26. ISSN 2215-4906 
características atravesadas por las teorías y los conceptos planteados. Lo cual, permite, sobre todo, el giro de la pregunta ¿qué es la danza? a ¿cuándo hay danza? Reconociendo el circuito artístico de la danza mexicana en el que se inserta la obra y todos sus actores. Se responde, finalmente, sobre el ejemplo, a la pregunta lanzada por Isse (2013) en el citado libro: ¿qué sería lo contemporáneo de las producciones de danza contemporánea del último lustro? Entonces, para fundamentar con éxito el presente análisis, se hace necesario no solamente abordar problemáticas generales del arte y de la danza contemporánea a nivel global, sino también un repaso, aunque sea superficial, de la realidad de la danza contemporánea en México. Será Haydé Lachino (2013) quién ofrezca claridad respecto al estado de la danza contemporánea en México:

Una parte importante de la crítica especializada, del público e incluso de los profesionales de la danza, muestran un profundo desconcierto ante propuestas escénicas que cuestionan y van a contracorriente de la idea normalizada que asume que la danza es un arte caracterizado por la lógica, natural y armónica sucesión de pasos, realizados por un cuerpo modelado por técnicas de danza, en donde alguien (el autor) tiene algo fundamental qué decir a otro (el espectador) (Lachino, 2013, p. 5).

Si, como dice esta autora, "para estos críticos, espectadores y creadores, el mundo no ha cambiado significativamente, [y] anclados en ideas de la danza heredadas desde el Renacimiento ... hoy demandan que la danza siga una inercia estética" (Lachino, 2013, p. $6)$, se deberá ser, en extremo, cauteloso respecto a la apropiación que, desde este contexto, se hace de las teorías y postulados aquí expuestos. En particular por el riesgo de, lejos de hacer un reconocimiento de lo propio, continuar la tradición de voltear la mirada a la hegemonía eurocentrista como directriz del cómo, el qué y el cuándo se hace arte. Es así como, de las palabras de Lachino (2013), emergen dos tipos de propuestas escénicas: aquellas que cuestionan y van contracorriente de la idea normalizada de danza, justamente, las que interesan al presente trabajo, y aquellas que aún pueden corresponderse con ideas de la danza heredadas desde el Renacimiento. Lo importante es, pues, que en un escenario como el mexicano, hacer danza podría aún corresponder, en gran medida, a postulados modernos y que, ciertas propuestas, como la aquí analizada, recién llegan como engranes articuladores de un nuevo pensamiento, los cuales apuestan por nuevos modos de producción que permiten dar cuenta del llamado por Danto (2006), arte posthistórico, aquel que resulta inmune a los manifiestos y que requiere de otra práctica crítica. De este breve "diálogo" entre Lachino y Danto, se hace más fácil seguir a Lepecki cuando dice que

cualquier danza que ponga a prueba y que complique su acto de presencia y el lugar dónde establecer el terreno de su ser, sugiere para los estudios críticos de la danza la necesidad de establecer un diálogo renovado con la filosofía contemporánea (Lepecki, 2008, p. 20). 
Y es a este diálogo renovado al que postula inscribirse, aspiracionalmente, un texto de la naturaleza del presente, al abordar una propuesta mexicana que, en su contexto, genera una nueva reflexión en torno al quehacer dancístico y lo que eso puede significar o contener. Se debe entender, para dar mayor sentido, tanto a lo anterior como a lo que viene, postulados como la posthistoria en el arte, el fin del arte, la transfiguración del lugar común de Arthur Danto y la Teoría institucional del arte de Dickie. Estos permiten comprender el movimiento de la post-modern dance como detonador de la danza contemporánea y de aquellas propuestas que logran, hacia el final de la segunda mitad del siglo pasado, definirse como arte. Todo esto, más por responder al también nuevo cuestionamiento de Goodman (en Isse, 2013), ¿cuándo hay arte?, que por intentar someterse a metarrelatos que venían sucediéndose y que intentaban decir cómo y qué es (o era) el arte. Si bien la idea de la muerte del arte viene de los análisis hegelianos, para fines prácticos, interesa el planteamiento hecho por Isse (reconociblemente atravesado por Danto) que:

La muerte del arte consiste en la disolución del mismo en cuanto a forma del espíritu y será en esta encrucijada donde se suscite la posible desaparición del arte. La desintegración, como síntoma del "después" [las comillas son del original], evoca las tensiones existentes entre la forma y el contenido, la exterioridad y la interioridad, el desequilibrio entre lo objetivo y lo subjetivo, la ruptura de la unidad de las obras artísticas en beneficio de una categoría que, desde ahora, fundamenta la [pos]modernidad: la accidentalidad o la fragmentación (Isse, 2013, p. 41).

Sirviéndose de esta misma idea para reafirmar que "la noción de fin del arte debe entenderse como el final de la era de las grandes narrativas, de los relatos abarcativos que intentaban legitimar un estilo o una determinada tendencia por sobre otras" (Isse, 2013, p. 43), para Isse Moyano, las características que comienzan a emerger en el arte reciente, lo único que hacen es evidenciar, que en realidad, "no hay ningún signo de agotamiento, sino todo lo contrario" (Isse, 2013, p. 46). Este mencionado no agotamiento es el que permite, al mismo autor, afirmar que la "posthistoria del arte no implica la muerte del arte, ... [sino que solo supone] que la era dominada por normativas artísticas llegó a su fin" (Isse, 2013, p. 46). Lo que se agota no es el arte, sino su tendencia a lo "puro" y disciplinar como garantía de calidad. La propuesta de Danto respecto a que "ningún arte está ya históricamente enfrentado contra ningún otro arte [y que ningún] arte es más verdadero que otro, ni más falso históricamente que otro" (Danto, 2006, p. 49), se vuelve, no solo comprensible, sino también signo de vitalidad al interior de la investigación y producción en todas las artes, incluida la danza.

Son las manifestaciones propias del después del arte, la emancipación del artista y de los objetos representados en las obras respecto a los contextos o relaciones sustanciales de la tradición, las que dan paso, entonces, a la posthistoria del arte y las que llevan a Danto a plantear la transfiguración del lugar común como acción necesaria y característica 
del arte contemporáneo. Lo cual, quita la atención del qué y del cómo para trasladarlo al dónde y al cuándo. Esta llamada transfiguración es la que permitirá "que la obra de arte se diferencie de los demás objetos ... a pesar de tener las mismas cualidades físicas" (Isse, 2013, p. 48). La idea ofrece total coherencia con el señalamiento de Goodman, citado por Isse (2013), respecto a que, la pregunta no debe ser qué es arte sino cuándo hay arte.

Es al ver la obra que debe producirse en el espectador la llamada transfiguración del lugar común, entendiendo que la obra ahora exterioriza una forma de ver el mundo, lo cual trasciende los postulados anteriores y dota de sentido los estudios realizados por Dickie (en Isse, 2013) respecto al placer desinteresado del espectador, frente a las obras de arte. El mismo que por años y sumado a la idea de belleza, era estudiado por la estética, la cual propuso que ya no es este el factor que todas las obras tienen en común. Dickie postula que no es sino, dentro del llamado mundo del arte del que forman parte los artistas, críticos, curadores, directores de galerías y museos, que funcionan las obras como tales y en el que se incluye también las concepciones que cada época tiene del arte, es decir, que depende de todo este engranaje de sistemas (y subsistemas) que suceda el hecho artístico y que una obra (o artefacto) devenga en arte (Isse, 2013). Asimismo, tanto Danto como Dickie, no proponen a priori estos conceptos. Como en todas las épocas, dichos estudios se desarrollan para tratar de explicar el arte que está sucediendo en su época y que es llamada posmodernidad. Época en la que el arte puede ser lo que quieran los artistas, en la que se comienzan a articular nuevos modelos de representación, en la que se apuesta por el discurso propio, uno que a su vez está imposibilitado para proponerse como único:

el posmodernismo es la posibilidad de mirar el pasado, tanto lejano como reciente, y de reivindicar abiertamente sus referencias, sus filiaciones, afirmando al mismo tiempo su pertenencia al mundo contemporáneo. Ser posmoderno es aprehender una cultura liberada de toda jerarquía de valor, es practicar una mezcla ecléctica que combina libremente los elementos del modernismo con la tradición reinterpretada. La novedad reside de alguna manera en la puesta en evidencia de lo necesario híbrido, del posible pluralismo de las escrituras (Isse, 2013, p. 53).

Sin perder de vista que, como afirma Isse Moyano, no se trata de un cambio fácilmente especificable en la apariencia del arte, sino en la manera en que este se ha situado al contexto (qué y cuándo), es el mismo autor quien da luz sobre características, si no visibles, sí distinguibles en el arte de hoy, con lo que llega a proponer que "también las normativas que han atravesado la historia de la danza se han extinguido. Los límites entre la danza y la cotidianeidad, entre el profesional y el público, entre el arte y la vida, se habrían vuelto difusos" (Isse, 2013, p. 51). Esta afirmación ya es, en sí misma, un entrenamiento básico para el ojo del receptor que demanda la danza contemporánea y sugiere, al mismo tiempo, caminos de búsqueda e investigación para nuevos creadores. Ahora bien, como afirma Lipovetsky 
estamos ante una nueva fase en la historia del individualismo occidental [en la que] la fe en el futuro, en la ciencia y en las vanguardias están siendo reemplazados por el individualismo hedonista, el sentimiento de reiteración y estancamiento, la autonomía privada indiscutida, la banalización de la innovación, la avidez de tranquilidad y realización personal inmediata, la neutralización del cambio en apatía (Lipovetsky en Isse, 2013, p. 59).

Entonces, se vuelve evidente el por qué las condiciones que pertenecen a la contemporaneidad son el empleo de nuevas tecnologías, la mezcla de géneros y materiales, la exploración de nuevas formas, la experimentación de nuevos campos artísticos, entre otros (Isse, 2013). En este contexto, es la versión contemporánea de la danza la que comienza a desarticular las relaciones de flujo, continuidad de movimiento, espacio escénico, entre otras, al ser la post-modern dance la encargada de borrar las fronteras entre el movimiento cotidiano y el artístico. Esto da pie a la llamada Danza Contemporánea, incluyéndose en el marco que contiene al universo del arte contemporáneo, a partir de su capacidad de transfigurar el lugar común y su participación en el mundo del arte (Isse, 2013, pp. 138-152).

Los postulados anteriores permiten el entendimiento contemporáneo del arte y de cómo este se inscribe en los múltiples aspectos de la vida cotidiana. Resulta cada vez menos identificable en cuanto tal, pero pone un acento en su construcción "sobre la base de [determinadas] interrelaciones y de la ausencia de fronteras entre las disciplinas" (Isse, 2013, p. 144). Desde las consideraciones anteriores, se vuelve posible un análisis de la obra Fit/MisFit, sin perder de vista el contexto mexicano de la danza, pero si sumando conceptos importantes revisados en este apartado. A partir de la idea de la muerte del arte, la posthistoria del arte, la transfiguración del lugar común de Danto y el mundo del Arte de Dickie es más fácil acceder a la recepción, construcción y carácter de la obra a analizar desde el pensamiento contemporáneo. La sinopsis que la compañía de danza contemporánea Lux Boreal propone en el dossier ${ }^{4}$ de Fit/Misfit, resulta una base para comenzar el análisis de la obra, ya que puede usarse casi a manera de hipótesis a comprobar a través de este:

Fit/Misfit pone cara a cara nuestra necesidad de pertenencia y el sentido de la individualidad. Cuatro bailarines, un espacio para compartir. Cuatro personajes que negocian su lugar para encajar de alguna manera entre las concesiones y la resistencia, llegando a acuerdos sin tener necesariamente un punto en común. Inmersos por el ambiente musical del Spaghe Western, se desarrolla un consenso cómico, entre lo patético y el entusiasmo, producto de combinaciones aleatorias e interacciones arquetípicas más que decisiones sensatas. Se ajusta, encuentra su lugar en un dejo de confianza, en la sensación de

\footnotetext{
4 Sinopsis transcrita del dossier proporcionado por LuxBoreal.
} 
pertenecer... no siempre con éxito. En una parodia de sí mismos, los intérpretes se dan a la tarea de resolver siendo lo que no son y, conforme a esa naturaleza, suponen lo que si son para satisfacer las aspiraciones del grupo (Compañía Lux Boreal, 2007, párr. 1).

Desde su sinopsis esta obra se propone como una creación contemporánea: desde la individualidad, la mezcla de estilos, las evocaciones a otras disciplinas y épocas, su aparente humor, el uso de la parodia, la utilización del juego desde su construcción, la complicidad con un público que sabe lo que recibirá de ellos y la transfiguración del propio bailarín en escena. Todas estas características retan al contexto advertido por Haydé Lachino (2013) en la escena mexicana pero, a su vez, son capaces de colocar a esta agrupación a la par de aquellas otras que, a nivel internacional, cuestionan con su quehacer cotidiano al arte, a la llamada danza, al movimiento, al cuerpo y, ante todo, a sí mismos. "Juguemos a encajar con el otro o en el lugar del otro" es la premisa que da inicio y que sostiene toda la obra. La tarjetas con enunciados que provocan la acción y las consignas para este accionar, con un interés particularmente espacial, son las que dan inicio a la primera parte de la obra y que, posteriormente, se convierten en contenedores de la misma, según Ángel Arámbula ${ }^{5}$ en una entrevista ${ }^{6}$ para el presente análisis. La investigación y la construcción del movimiento, a partir del dejarse llevar por el mismo; de limitaciones temporales; desplazamientos migratorios que descolocan a los mismos artistas-intérpretes-creadores-colaboradores y la experimentación desde de la improvisación; los espacios abiertos a la continua espontaneidad en escena -a partir de un conocimiento profundo de la obra y la investigación que proponeson las herramientas que hacen posible el significar todo un flujo de movimiento, de energía, de intención, en un puño cerrado, por ejemplo, y convertirlo en danza contemporánea.

La obra referida apuesta, de manera muy consciente, y como menciona Isse, porque no es la danza, en este caso, lo que se agota, sino su tendencia a lo "puro" y disciplinar como garantía de calidad. Sin sacrificar esta última, no existe, a lo largo de la puesta en escena, un lenguaje dancístico homogéneo, lo cual resulta evidente a través de cuerpos que vienen de formaciones técnicas diversas (ballet, jazz, contemporáneo) y sin la más mínima

${ }^{5}$ Bailarín, coreógrafo y docente. Miembro fundador y codirector de la Compañía de Danza Lux Boreal. Su línea de investigación lo ha llevado profundizar en la enseñanza de sistemas de entrenamiento, diseñando en 2013 la técnica "Accionar el Cuerpo". Desde 2006 se desempeña como director académico del Diplomado de Danza Contemporánea y Producción Escénica de Tijuana, en colaboración con la Universidad Pedagógica Nacional y el Instituto de Cultura de Baja California.

${ }^{6}$ La entrevista fue realizada por la autora el 20 de setiembre del 2017, en Tijuana México.

ESCENA. Revista de las artes, 2018, Vol. 78, Núm. 1 (julio-diciembre), pp. 10-26. ISSN 2215-4906 
pretensión de igualar las formas o las energías, pero, la apuesta no se restringe a esto. De principio a fin, sin negar las destrezas corporales de cada uno de sus integrantes, hay un espíritu que prefiere lo cotidiano frente a lo técnico.

\section{Imagen 1. Lux Boreal: Fit/Misfit}

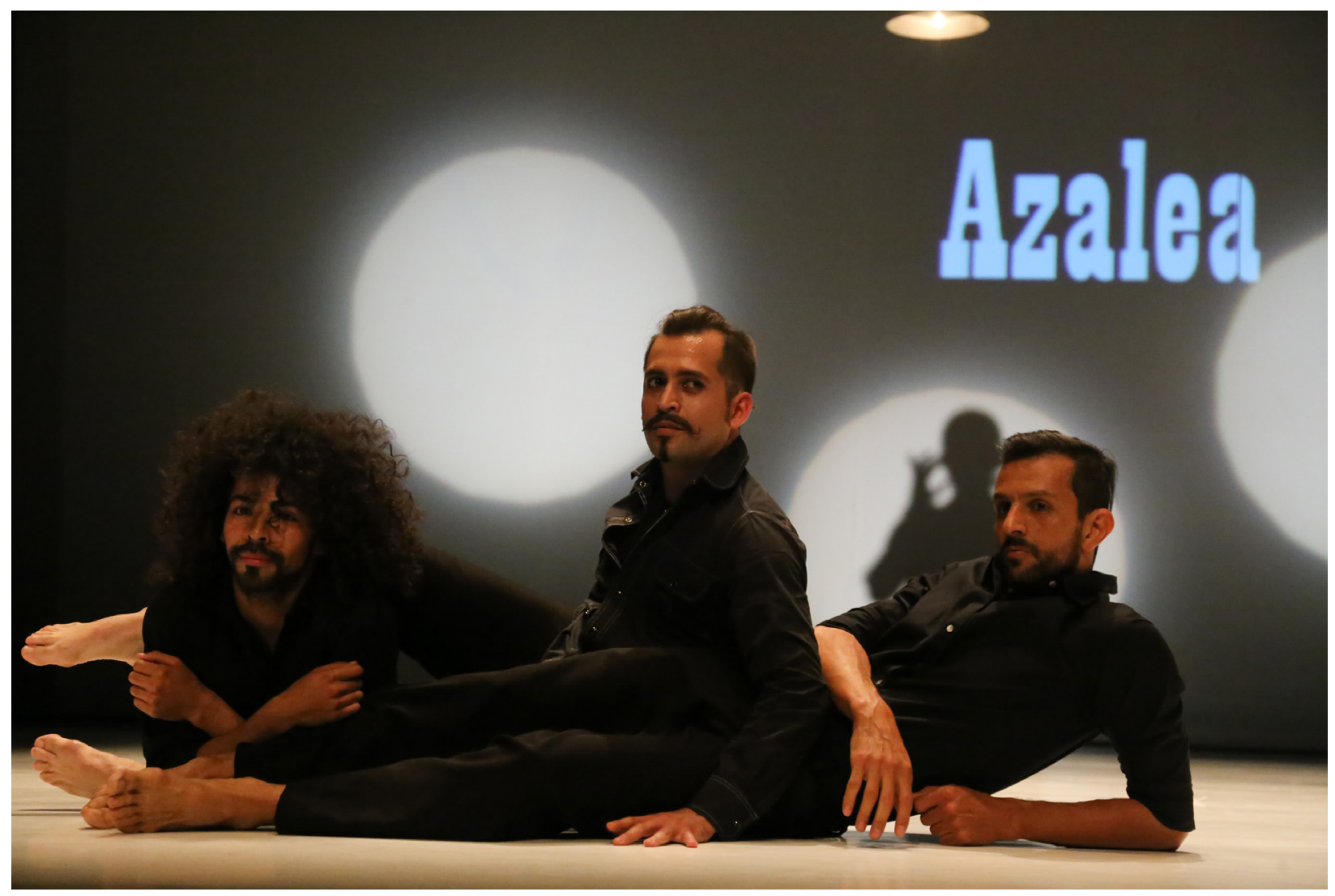

Fuente: Archivo de la Compañía

Lo técnico pierde completamente su importancia, podría no existir en absoluto y la obra conservaría una riqueza fundamentada en acciones tan básicas como caminar, correr u observar. Incluso, la acción de bailar aparece revestida con el velo de la operación de pertenecer. Lux Boreal no se sube a escena a bailar, sino a participar de una realidad social frente a la que el espectador se siente identificado. Es como si su entrada a escena sucediera al 
ser empujados por algo o alguien para estar ahí, tal si fuera un reflejo de cómo momentos y acciones cotidianas son arrojados a la obra para ser llamados danza contemporánea, sin artilugios, sin más que lo que son cotidianamente, seres humanos.

El vestuario negro y su austeridad resulta un elemento capaz de hablar de la esencia del humano y, simultáneamente, de resaltar todo aquello de lo que se vale la sociedad -y el individuo dentro de esta- para pertenecer a ella o diferenciarse, a partir del otro. El agregar elementos particularmente rojos al personaje de Azalea, que pareciera querer pasar inadvertida, acerca a la contradicción social frente a la que se plantea el individuo en el día a día: la necesidad del artilugio como estrategia de pertenencia. Estos, lo hacen sumar elementos hasta desconocerse a sí mismo, pero sin dejar de ser. Los cambios de vestuario en escena (que no son vistos); los colores llamativos; la imposición de un vestuario igual a otro, como clara metáfora del tener que parecerse a alguien más; el retorno al propio personaje y todas las estrategias sociales con las que se convive diariamente. Todo esto para que, al final, los dejen situados justo en el mismo sitio que al principio, buscando encontrar esos huecos que parecen conceder la posibilidad de ocupar el lugar de otro.

Pero tal como el arte contemporáneo en general, Fit/Misfit no se conforma con la multiplicidad de técnicas dancísticas o la inserción de elementos cotidianos, ya que ofrece al espectador la evocación de un lenguaje cinematográfico, a través de la proyección momentánea de los nombres de los intérpretes. Sumado al diseño sonoro, estos llevan la escena a producciones ubicadas en el viejo oeste y su ritmo particular. La obra busca esos momentos justos en los que cada individuo es y toma importancia dentro del conjunto, pero, al mismo tiempo, es desdibujado (transfigurado) en términos de realidad. Se borra la línea entre aquello que son los intérpretes como individuos en lo cotidiano y el personaje que se construye a partir de las relaciones en escena.

Si bien la sinopsis propone cuatro personajes, no se puede pasar por alto la ruptura y sorpresa que se produce a través de la presencia en escena de "Henry", quien, en apariencia, no es parte de lo que sucede "dancísticamente". Resulta un punto de quiebre, de fragmentación, de aparente incoherencia y una fuerte tendencia hacia la individualidad e incluso lo autobiográfico, por el rol que desempeña Henry ${ }^{\top}$ en la agrupación de manera cotidiana. Tal

7 Miembro fundador y codirector de la Compañía de Danza Lux Boreal. Ha contribuido al desarrollo y crecimiento del colectivo y sus plataformas de creación, exposición y educación. Su línea de investigación lo ha llevado a profundizar en técnicas de movimiento y creación relacionadas para danza contemporánea. Paralelamente ha investigado la aplicación de la iluminación y el video en la escena. Ha colaborado con montajes interdisciplinarios donde la danza juega un papel importante en teatro, televisión e intervenciones de naturaleza urbana. Ha incursionado en la integración del

ESCENA. Revista de las artes, 2018, Vol. 78, Núm. 1 (julio-diciembre), pp. 10-26. ISSN 2215-4906 
vez no sea casual, dentro del discurso social que le es inherente a la obra, que sea un quinto personaje -uno no considerado- el que no hizo lo mismo que el resto, el que no trató de encajar o pertenecer, el que no quiso buscar el lugar de nadie; el que aparece de pie mientras todos los demás se encuentran en el piso y el que regresa a su espacio sin sentirse invadido por ningún otro, vestido de negro, sin más. Mientras sus compañeros se encuentran ya con capas de ropa que pueden equipararse a las capas de lecturas que ofrece este hecho.

Fit/Misfit no es una obra que aspire a entrar en el universo de lo híbrido, o que se pretenda capaz de confundir respecto a su naturaleza, el uso del juego, del humor, el pluralismo estético, el uso de movimientos cotidianos entrecruzados con los que, históricamente, tienden al status de "dancísticos". La dislocación de la música como mero soporte, la excelencia técnica pasada inadvertida, el sutil uso de multimedia y el poco interés por imponerse barreras disciplinares, permiten que esta propuesta habite la época que sucede después del arte, esa llamada por Danto post-historia, que no implica la muerte del arte, sino el alejamiento de toda narrativa. Son justamente estas las posibilidades que detonan y permiten las características mencionadas que alejan a la puesta del posible agotamiento artístico que algunos apocalípticos pretenden ver. En el mundo de repeticiones planteado por Fit/Misfit, la intención narrativa desaparece. Se agregan elementos, relaciones, dinámicas, pero aquello que se propone como principio, se mantiene como único momento e, incluso, como final. Si bien permite que el espectador construya, a partir de él mismo y su contexto, lecturas específicas, la obra se propone un continuo juego entre los intérpretes y su necesidad de pertenecer, de convertirse, aparentar o ser aquello que se necesita para habitar el espacio del otro y sus relaciones posibles.

Asimismo, se debe mencionar, también, que esta obra resulta un excelente ejemplo para hablar de la transfiguración del lugar común. Si bien en las artes plásticas podría resultar casi evidente, en las artes del movimiento y de la presencia las relaciones que se establecen entre cuerpo-objeto y lugar-escena suelen complicar la transfiguración. El uso que hacen de la proyección multimedia, con este propósito o no, resulta la estrategia perfecta para la transfiguración del cuerpo de los bailarines. Lo que aparece proyectado no son nombres de personajes ficticios, Ángel realmente se llama Ángel, Azalea es Azalea en su vida cotidiana, Raúl es Raúl y al Chino lo conocen como Chino. Es a ellos a quienes se ve, es su cuerpo, son ellos, esos ellos con quienes se convive fuera de esa escena pero inmersos en ella y eso lo modifica todo, lo transfigura.

video en su propuesta dancística . Director artístico del Diplomado de Danza Contemporánea y Producción de Tijuana, en colaboración con la Universidad Pedagógica Nacional y el Instituto de Cultura de Baja California.

ESCENA. Revista de las artes, 2018, Vol. 78, Núm. 1 (julio-diciembre), pp. 10-26. ISSN 2215-4906 
Se mezcla la identidad de cada uno de ellos, como seres humanos y todo su cotidiano, con un líder ruso, un galán, un sujeto bastante despreocupado y una chica tímida, para construir un otro a partir de ellos. Pero, al mismo tiempo, se alejan de lo que son (aunque no del todo), mientras se encuentran en ese tiempo-espacio en que se trata de pertenecer, de querer encajar en el otro y se encuentran limitados para hacerlo; se convierten en esos signos capaces de significar algo más en el mundo común. Es el resultado de una sutileza capaz de hacer suponer que en "forma" y en apariencia, la danza no ha cambiado. Sin embargo, sitúan, de manera distinta, el contexto, el qué y el cómo se esta produciendo la danza de hoy en día, lo cual reta, desde la identificación intelectual, al mundo del arte descrito por Lachino (2013) pero que, en definitiva, no es el único que rodea a la compañía. Cada espectador deberá de producir el personaje que ve, esto dependerá de su conocimiento o desconocimiento de la compañía, de sus antecedentes, de las historias de sus integrantes, del contexto en que es vista, incluso de la significación que se le de a elementos de vestuario determinados. Así, se construye de manera distinta al ruso optimista en México que en Cuba y resulta, en cualquier caso, un individuo que trata de pertenecer a un grupo social determinado, también dictado por cada espectador en particular.

Fit/MisFit resulta, finalmente, una obra de análisis sencillo desde los postulados de la Teoría Institucional del arte de Dickie, para quien el llamado circuito del arte (instituciones, galerías, críticos, espectadores y artísticas) es lo que establece cuando una obra puede ser llamada arte, en este caso, cuando puede ser llamada danza contemporánea. Si es el mundo del arte el que da respuesta a ¿cuándo hay arte o cuándo hay danza contemporánea? en Fit/Misfit se citan todos los sistemas de dicho circuito. Por un lado, Lux Boreal Danza Contemporánea y sus colaboradores, Iseli-Chiodi Dance Company, en este caso, se proponen hacer danza contemporánea y son reconocidos por tal circuito como coreógrafos e intérpretes de él. Con esto, ya tienen ganado el subsistema referente al quién hace danza. Por otro lado, existe un reconocimiento hacia ambas compañías, por parte de distintas instituciones que los "avalan" como artistas de una destacada calidad. Lux Boreal es apoyado por el programa México en Escena en su 5ta emisión, por el Instituto de Cultura del Gobierno del Estado de Baja California, y el Instituto Municipal de Arte y Cultura de Tijuana. Iseli-Chiodi trabaja con el apoyo del Consejo de las Artes de Irlanda, el Tipperary Excel Arts Centre, el Servicio de Artes del Sur Tipperary County Council y el Tour con Culture Ireland como parte del programa de la Presidencia de la UE, con lo que abarca el reconocimiento de un amplio espectro del mundo del arte.

La presencia de Lux Boreal con Fit/MisFit en diferentes festivales internacionales desde su creación, en 2013, hasta la fecha, explica la aceptación de la obra, tanto por parte de curadores especialistas, como por parte del público de danza. Mismo que responde frente a su propuesta con una profunda reflexión entre las risas desprendidas durante la 
presentación de la obra. Cabe mencionar dentro de este mundo del arte, que la agrupación se hace presente en medios como the journalist, examiner.com, sandiegostory.com (entre otros) con excelentes críticas de Stephen White, Chris O'Rourke y Janice Steinberg, respectivamente. En efecto, Steinberg es quien habla de las referencias a la cultura pop, los momentos de humor, la influencia western tanto visual como sonora, entre otras características, como factores que le permiten considerar Fit/MisFit como una pieza post-modernista y que el presente análisis lleva al terreno de lo contemporáneo.

Entonces, sí hay danza contemporánea cuando creadores de la danza se proponen hacerlo, cuando instituciones culturales reconocen a estos creadores como tales, e incluso les proporcionan los medios para la producción de determinados proyectos. Cuando la crítica especializada reconoce la danza contemporánea en las obras y un público entrenado se permite disfrutar desde el goce y desde el compromiso intelectual sí hay danza contemporánea. Cuando el imbricado sistema, llamado por Dickie, mundo del arte, se articula exitosamente para afirmarlo, no se puede dudar que Fit/MisFit se convierte en un contenedor de Danza Contemporánea. Finalmente, Fit/Misfit permite seguir a Vattimo (en Isse, 2013) cuando advierte que en el arte contemporáneo:

la obra no apunta a alcanzar un éxito que le de derecho de colocarse dentro de un determinado ámbito de valores... el éxito... consiste en hacer problemático dicho ámbito, en superar sus confines... la capacidad que tenga de poner en discusión su propia condición como tal (Vattimo,1996 en Isse, 2013, p. 153).

Y es que, si bien Fit/Misfit es una obra que alcanza el éxito correspondiente a ese determinado ámbito de valores y se sigue presentando cinco años después de su creación, también es cierto que podría problematizarse en términos de su construcción. Lo que vemos es la repetición de un par de secuencias de movimiento sumadas a acciones básicas, lo que permite poner en discusión su condición como danza. Sin embargo, las relaciones que se establecen entre los bailarines, la suma de elementos de color en la escena, el tiempo con que desarrollan dichas secuencias, incluso, la presentación de los propios intérpretes logran comunicarse estéticamente de una manera contundente y efectiva con el espectador.

La apertura a momentos de improvisación, de acción y reacción frente a las desiciones del otro, el claro manejo espacial, entre otros aspectos, dejan claro que, más allá de la utilización del azar y el juego, Fit/Misfit ofrece una calidad y un compromiso con la producción contemporánea de danza. Además, evidencia una clara comunicación en escena y una definición en la propuesta, que reiteran en cada toma de decisión en la puesta (y en su producción). Se muestra el interés en una estética propia de la compañía, al poner énfasis, más que en un lenguaje corporal, en la producción de imágenes escénicas que, en movimiento, resulten características de la agrupación y la diferencien de otras. Piénsese

ESCENA. Revista de las artes, 2018, Vol. 78, Núm. 1 (julio-diciembre), pp. 10-26. ISSN 2215-4906 
en el uso de la consola de audio e iluminación en escena, el uso de manera sutil de multimedia, la proyección de sus propios nombres (que desvían la obra hacia lo autobiográfico, también característica de las producciones contemporáneas), el uso de la sorpresa que, en este caso, recae en la aparición de Henry. Todos estos elementos que, lejos de aparecer como fórmulas repetidas de sus creaciones, aparecen como sellos o firmas distintivos de la calidad y la búsqueda artística de Lux Boreal.

Imagen 2. Lux Boreal: Fit/Misfit

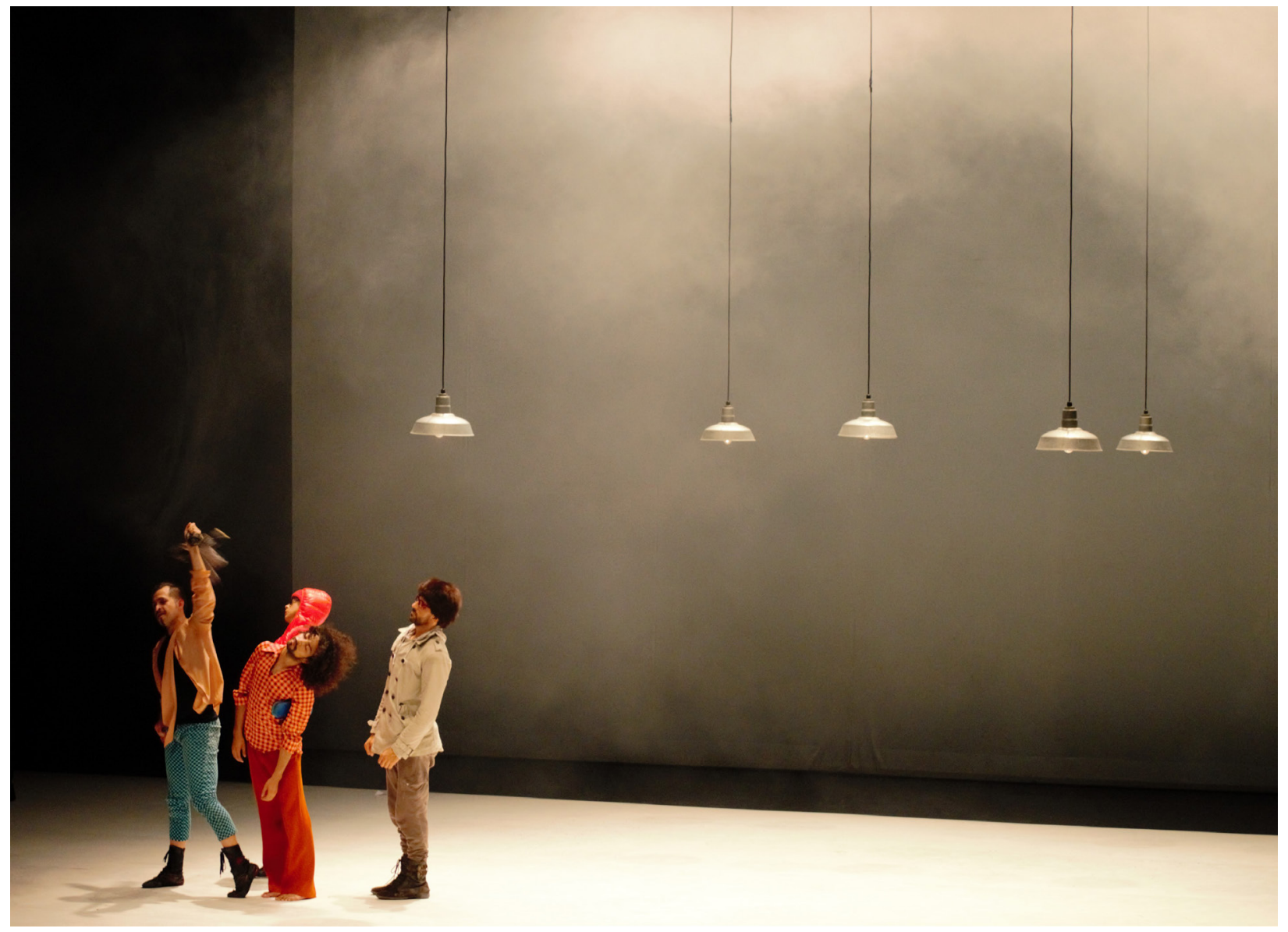

Fuente: Archivo de la Compañía 
Al enfrentarse a la pregunta planteada por Isse Moyano de ¿qué sería lo contemporáneo de las producciones de danza contemporánea del último lustro? Y a la respuesta que el mismo autor proporciona al sentar características específicas (aunque no necesariamente visibles) de estas nuevas creaciones, se descubre, fácilmente, que una propuesta como Fit/ Misfit forma parte de los nuevos modelos de producción en el arte posthistórico. Además, al seguir el marco teórico dentro del que se desarrolla la presente reseña/análisis, se evidencia que esto se debe a la entera libertad de la que gozó la obra en su construcción y presentación. Justamente, por la transfiguración del lugar común que permite comprender la sutil diferencia entre lo artístico y lo banal -real o cotidiano en este caso- y por la clara estetización general de la existencia, insertándose con éxito en el mundo del arte.

Regresando, entonces, a la sinopsis que fue planteada como hipótesis, más allá de la claridad en el mensaje, respecto a la necesidad inherente a todo ser humano de pertenecer y su simultáneo sentido de la individualidad, lo que promete es comprobado en escena. El espacio que comparten los bailarines se construye en cada presentación a partir de la libertad que la misma obra permite y del compromiso de sus intérpretes frente a esto. Lo cual, hace posible y evidente las combinaciones aleatorias que son prometidas. La posibilidad, como planteamiento inicial de hacer concesiones o resistir para llegar a acuerdos, aunque no se tenga nada en común, resulta en sí misma una característica de la época contemporánea. Esto da como resultado una pieza que logra evidenciar al arte contemporáneo, a través de la danza, como testigo de la actualidad. El uso ambiental de la música, sumada a arquetipos cinematográficos de cierto estilo western, permite que la danza conviva en perfecta armonía con otras disciplinas, sin cerrar por esto la posibilidad de sorpresa y sin depender de ellas. Así se logra una obra que, en toda su apertura, resulta perfectamente cerrada en términos estéticos e incluso estilísticos desde lo contemporáneo del arte.

Fit/Misfit no puede evitar, entonces, resultar autoreferencial (aunque tal vez sin proponérselo) frente al contexto planteado por Lachino (2013). Ese contexto que sigue esperando características inmanentes que definan a la danza como danza, con lo cual, suma una evidencia más de su naturaleza contemporánea. Si se trata de un contexto en el que las obras de danza deben parecerse o contener características específicas para ser definidas como tal, para encontrar o para lograr ocupar un lugar dentro de ese universo llamado danza (algunas veces sin éxito, como se plantea en la sinopsis), Lux Boreal retrata la escena de la danza nacional mexicana de manera brillante. Curiosamente, esto se da a partir de correr límite de dicho universo y descolocar al espectador-crítico al que refiere Lachino. Desde aquí, Lux Boreal no solo resulta provocador con esta y con otras propuestas escénicas, sino que, asume también como un reto la continua búsqueda de nuevas formas de producción, que les permitan poner en crisis otros modelos. Para ello cuentan con programas creados 
Lux Boreal: Fit/Misfit bajo la lupa del arte contemporáneo y sus nuevos modelos de producción Artículos

específicamente para acercarse a todos los públicos y asumen la tarea como capacitadores de espectadores-receptores competentes y abiertos a posibles redefiniciones de la danza como arte escénico.

\section{Referencias}

Compañía Lux Boreal. (Agosto 2007). Dossier para la presentación de la obra. Tijuana, México.

Danto, A. (2006). Después del fin del arte. El arte contemporáneo y el linde de la hisoria. Buenos Aires: Paidós.

Danto, A. (2004). La transfiguración del lugar común. Buenos Aires: Paidós.

Dickie, G. (2005). El círculo del arte. Buenos Aires: Paidós.

Isse, M. (2013). La danza en el marco del arte moderno contemporáneo: los nuevos modelos de producción. Buenos Aires: Instituto Universitario Nacional del Arte.

Lachino, H. (2013) ¿Qué significa políticamente para nosotros la danza contemporánea? Fluir. Revista mexicana de danza contemporánea. Recuperado de http://revistafluir.com.mx/ misa-brevis/¿que-significa-politicamente-para-nosotros-la-danza-contemporanea.html

Lepecki, A. (2008). Agotar la danza. Performance y política del movimiento. Alcalá: Centro Coreográfico Galego, Mercat de les Flors.

Lipovetsky, G. (2008). La era del vacío. Buenos Aires: Anagrama.

Vattimo, G. (1996). El fin de la modernidad. Nihilismo y hermenéutica en la cultura posmoderna. Barcelona: Gedisa. 